\title{
Non-Newtonian Behavior Effect on Gas-liquid Mass Transfer using an Anchor Impeller for CSTR Bioreactors: A CFD Approach
}

\author{
Lilibeth Niño ${ }^{1 *}$, Mariana Peñuela' and Germán Ricardo Gelves² \\ ${ }^{1}$ Department of Chemical Engineering, Universidad de Antioquia. Carrera 53 N. ${ }^{\circ}$ 61-30. Medellín, Colombia; \\ lilicarininolop@gmail.com, marianapp@gmail.com \\ 2Department of Environment, Universidad Francisco de Paula Santander. Av. Gran Colombia 12E-96, Cúcuta, \\ Colombia; germanricardogz@ufps.edu.co
}

\begin{abstract}
Objectives: $k_{L} a$ mass transfer coefficient was predicted using CFD (computational fluid dynamics) for analyzing non-newtonian effects on gas liquid mass transfer in a $10 \mathrm{~L}$ bioreactor stirred with an Anchor Impeller. Methods/Statistical Analysis: The set up bioreactor configurations were defined by typical culturing conditions used for fungi organism. Bubble breakage frequency and coalescence rate were simulated using Luo - Colaloglou and Tavlarides models and PBM approaches, respectively. Simulated results from different shear rates due to non-newtonian behaviour are compared by analyzing its influences in bubble size and power input. Findings: A clear relationship between high levels of shear rates and small bubble sizes is found in this work. The later is also associated with the high values of $k_{L} a$ simulated ( $\left.270 \mathrm{~h}-1\right)$ and compared to levels found at low shear rates (62 h-1). Application/Improvements: Impressed by these findings new design optimizations for non-newtonian bioprocessing applications would be improved using CFD.
\end{abstract}

Keywords: Anchor, Bubble Coalescence, Non-Newtonian, Sauter Diameter, CFD

\section{Introduction}

Mixing of non-Newtonian fluids is one of the most difficult constraining in Bioprocess engineering Field since viscosity exerts a resistance to fluid deformation. This problem increases in multiphase fluids related to bubble interactions because it must be broken for oxygen can be transfer to culture media. Because oxygen transfer controls reaction rates in a bioprocess, it is considered a limiting factor that significantly affects overall productivity ${ }^{1}$.

The most common application occurs in the fungi cultivation at high viscosity levels ${ }^{2}$. The later affects the oxygen transfer rate and leads the process to gradients and poor mixed zones in a bioreactor. Consequently,mass transfer is proportional to biomass concentration, which means that constrains due to mass transfer and mixing are expected, leading the bioprocess to lots of productivity ${ }^{3}$.

Often bioreactors are configured with stirring system to conserve homogeneous operating conditions. Anchor impellers are well known for its common application in non-newtonian fluids and its ability for avoiding stagnation at bioreactor walls zones ${ }^{4}$. CFD is a simulating tool used for predicting bubble behaviour in reactors by simulating coalescence and breakage phenomena focusing on inhomogeneous zones.

Nowadays, CFD is used for in device type Impellers, including from one phase model $s^{5-7}$, to its implementation for modeling bubble size behaviours in gas - liquid systems $s^{1,8,9}$.

*Author for correspondence 
Although several works have been applied in understanding Anchor flow patterns, bubble size behaviour and rheological effects on mass transfer has not been studied so far. Based on the later there is weakness knowledge in gas liquid hydrodynamics for understanding Anchor device abilities. For this reason new design optimizations for non-Newtonian bioprocessing applications would be improved using CFD. Hence it is the main propose of this contribution to analyze bubble interactions caused by rheology in an Anchor Impeller using a Computational Simulation for mass transfer analysis.

\section{Materials and Methods}

An Anchor impeller for stirring 10 liters tank was simulated using CFD shown in Figure 1. The air dispersion does it by a ring sparger. The set up bioreactor configurations were defined by typical conditions used for filamentous cultures: $N_{\mathrm{i}}$ and vvm are set up at 200, 400 and $600 \mathrm{rpm}$ and $1.0 \mathrm{vvm}$, respectively. Ansys Fluent 13.0 software was used for CFD calculation. (a)

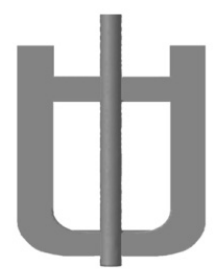

(b)

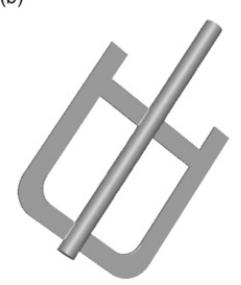

(c)

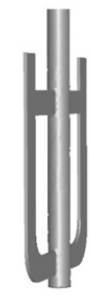

Figure 1. Helical Impeller. (a) Front View, (b) Diagonal View, (c) Cross section.

The finite volume method is used to discretize conservation equations in algebraic equations for all phases ${ }^{10}$. The Eulerian model was used to solve momentum and continuity equations. The Pressure-Velocity Method is used for coupling pressure and velocity via interfacial exchange coefficients. For modeling rotating zone the MRF (Multiple Reference Frame) model was applied.

Turbulence is modelled based on the dispersed turbulence $k-\varepsilon$ model and the powerlaw modelwasused for simulatingviscosity. Shearstress (shearratesrange: $1-100 \mathrm{~s}^{-1}$ ) in $0.25 \%$ xanthan gum ${ }^{11}$ was analyzed via viscometer to calculate rheological parameters (Figure 2) to be included in the CFD model. Results are $k: 0.28 \mathrm{~kg} / \mathrm{ms}$ and $n: 0.37$.

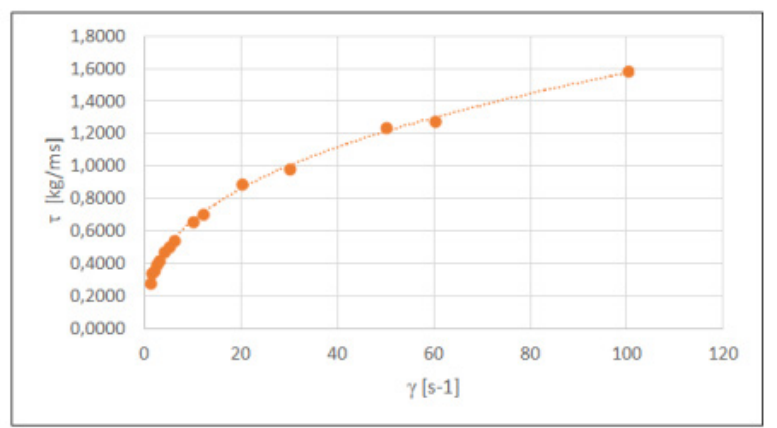

Figure 2. Rheogram for Parameter estimation (0.25\% xanthan gum).

For CFD model verification Impeller Power input $P$ was calculated as ${ }^{1}$ :

$$
P=N_{p} \rho N_{i}^{3} D_{i}^{5}
$$

With $N_{P}$ The power number, $\rho$ density, $N_{i}$ Stirring velocity, and $D_{i}$ Impeller diameter.

Bubbles are discretized using the discrete method ${ }^{11,12}$. Eddies increase the particle surface energy for causing breakage. The increase in bubble surface energy to a critical value causes the breakup ${ }^{13}$. The Coalescence model ${ }^{14}$ was used to simulate coalescence by considering bubble collision due to buoyancy, turbulence and laminar shear.

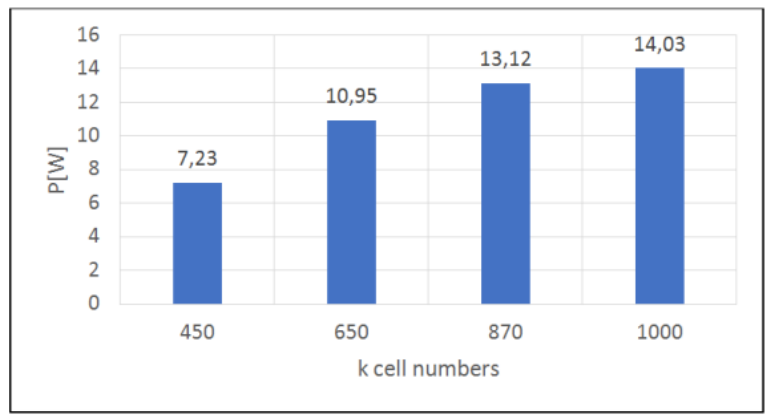

Figure 3. Mesh sensibility analysis.

Different grid sizes meshed were estimated for a sensitivity study (Figure 3): 450, 650, 870 and 1000 k cells. A grid-independent solution was reached at $1000 \mathrm{k}$ cells. 


\section{Results}

The main goal of this research is to simulate bubble size interactions caused by rheology in an Anchor Impeller using a CFD for mass transfer analysis. Special focus of $k_{L} a$ simulations is also showed using fluid dynamics to identify the influence of different mixing velocities on gas-liquid hydrodynamics for non-Newtonian fluids. Figure 4 shows the air volume fraction.

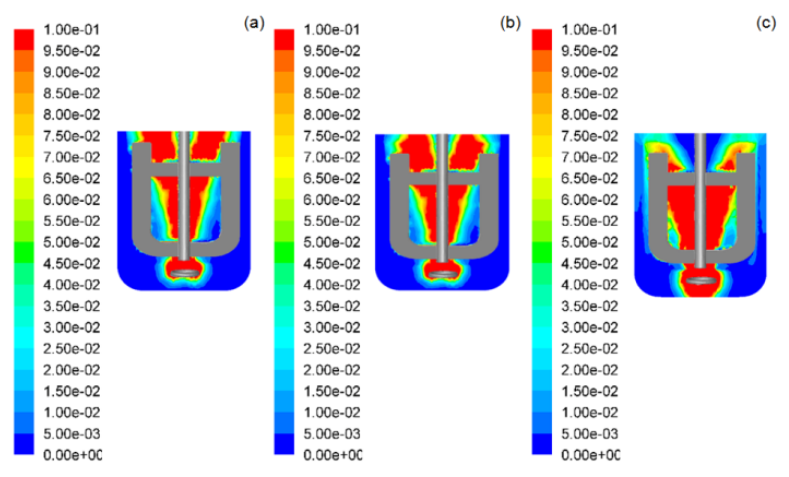

Figure 4. Air volume fraction [-]. Anchor Impeller. (a) $N_{i}$ : $200 \mathrm{rpm}$; (b) $N_{\mathrm{i}}: 400 \mathrm{rpm}$; (c) $N_{\mathrm{i}}: 600 \mathrm{rpm}$.

Figure 3 shows an inhomogeneous air dispersion in regions closed to Anchor device and reactor walls, which is not released by increasing mixing speed.

Shear rate in non-Newtonian fluid can be defined as the rate at which a fluid deforms. Figure 5 shows shear rate calculations from different stirring velocities. It was found in this research that shear rate, positively influences bubble size and the $k_{L} a$ values, respectively (Figures 6-7). The latter are main criteria for being considered during a design optimization stage for a stirring-aeration device, since it generates important information to determine how resistance due to viscosity in non-Newtonian fluids can be overcome. The latter is also a clear evidence of viscosity resistance affecting the mixing process.

Figure 6 shows the simulations of bubble mean diameter (Sauter diameter) generated by the breakup and coalescence phenomenon. Interestingly, low values of $\sim 2.0 \mathrm{~mm}$ are found closed to Impeller blades in the transverse areas of pumping direction. Also, for all cases, the smallest Sauter diameter is calculated in the bottom of bioreactor. These regions reflect relatively high rates of bubble breakage due to high levels of: turbulent dissipation

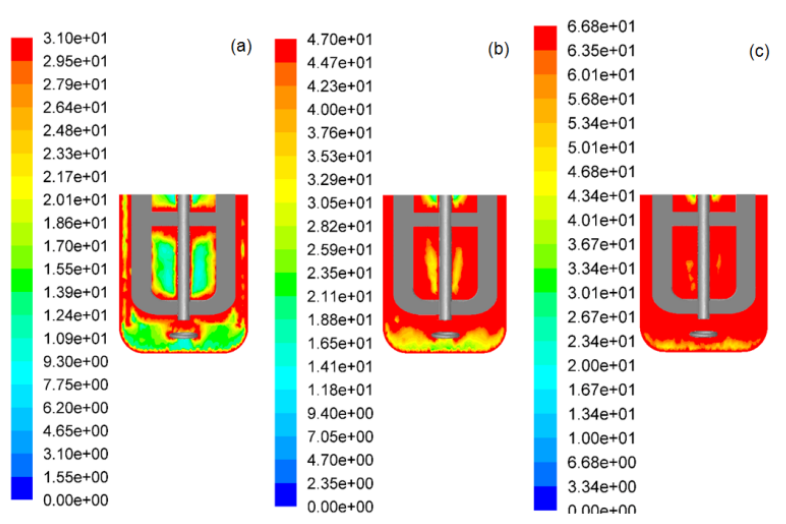

Figure 5. $\gamma$ Shear rate $\left[\mathrm{s}^{-1}\right]$. (a) $N_{\mathrm{i}}: 200 \mathrm{rpm}$; (b) $N_{\mathrm{i}}: 400 \mathrm{rpm}$; (c) $N_{\mathrm{i}}: 600 \mathrm{rpm}$.

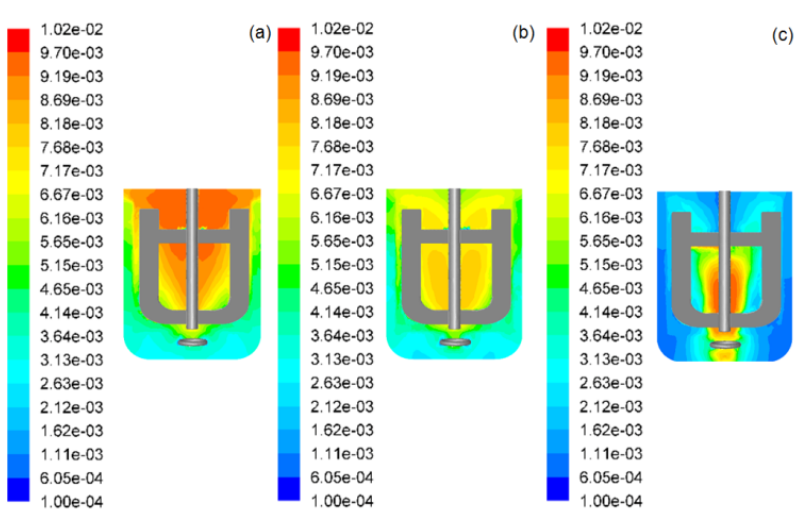

Figure 6. Sauter Diameter $[\mathrm{m}]$. Anchor Impeller. (a) $N_{\mathrm{i}}: 200$ rpm, (b) $N_{\mathrm{i}}: 400 \mathrm{rpm}$, (c) $N_{\mathrm{i}}: 600 \mathrm{rpm}$.

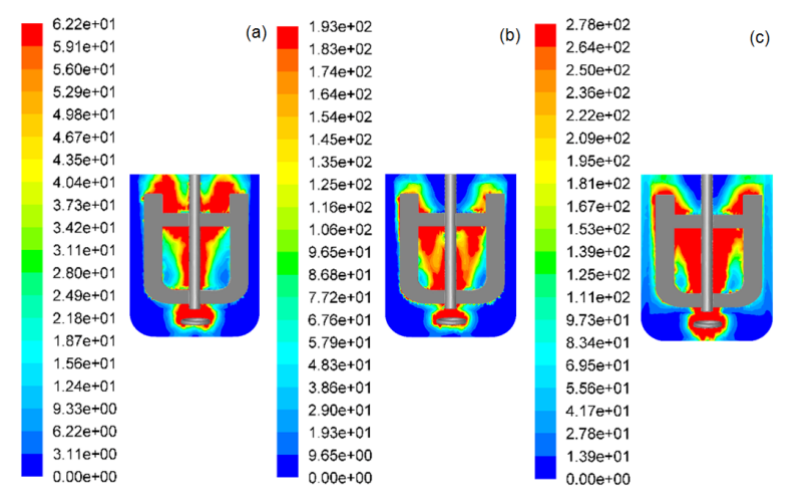

Figure 7. $k_{L} a[1 / \mathrm{h}]$. Anchor Impeller. (a) $N_{\mathrm{i}}: 200 \mathrm{rpm}$, (b) $N_{\mathrm{i}}$ : $400 \mathrm{rpm},(\mathrm{c}): N_{\mathrm{i}} 600 \mathrm{rpm}$.

energy and shear rate in areas closed to Anchor Impeller and walls. 
They $k_{L} a$ calculations are designed as a main factor for analyzing bubble interactions. For interacting $k_{L} a$ to hydrodynamics the Higbies penetration theory was implemented $\frac{15}{5}$ the interfacial area is limited by gas local fraction and mean local Sauter diameter. It is found is a clear dependence of bubble size on $k_{L} a$ values showing high values of $k_{L} a$ at the smallest level of bubble size.

CFD model verification is performed from Power Input $\mathrm{P}$ calculations from CFD and compared it with a common correlation (1) useful for mixing applications as shown in Table 1. Calculated values from correlation (1) identified integral $P$ values of $13.97,111.80$ and $377.33 \mathrm{~W}$ for 200,400 and $600 \mathrm{rpm}$, respectively, that fit very well to the simulations. The accurate of these results related to $\mathrm{P}$ calculation verifications is and evidence for the potential applicability of the CFD for future optimizations.

Table 1. CFD model verification from power input $\mathrm{P}[\mathrm{W}]$ determinations

\begin{tabular}{|c|c|c|c|c|c|}
\hline \multicolumn{2}{|c|}{200 rpm } & \multicolumn{2}{c|}{400 rpm } & \multicolumn{2}{c|}{600 rpm } \\
\hline $\begin{array}{c}\mathrm{P}[\mathrm{W}] \\
\text { CFD }\end{array}$ & $\begin{array}{c}\mathrm{P}[\mathrm{W}] \\
\text { Eq. (1) }\end{array}$ & $\begin{array}{c}\mathrm{P}[\mathrm{W}] \\
\text { CFD }\end{array}$ & $\begin{array}{c}\mathrm{P}[\mathrm{W}] \\
\text { Eq. (1) }\end{array}$ & $\begin{array}{c}\mathrm{P}[\mathrm{W}] \\
\text { CFD }\end{array}$ & $\begin{array}{c}\mathrm{P}[\mathrm{W}] \\
\text { Eq. (1) }\end{array}$ \\
\hline 14,03 & 13,97 & 103,04 & 111,80 & 326,73 & 377,33 \\
\hline
\end{tabular}

Different scenarios are observed for $k_{L} a$ values. From $62 \mathrm{~h}^{-1}$ to levels above $270 \mathrm{~h}^{-1}$ are observed (Figure 7), depending on the agitation conditions evaluated. Results found here are clear evidence of shear rate on the $k_{L} a$ mass transfer coefficient.

\section{Conclusions}

The bubble size interaction from gas liquid mass transfer in an Anchor Impeller is analyzed using CFD. Impressed by these findings new design optimizations for nonnewtonian bioprocessing applications would be improved using CFD. Shear rate and bubble size interactions can be treated as main starting point for improvement of operating conditions in non-newtonian fluids due to its influence on hydrodynamics.

\section{Acknowledgments}

This work was conducted in cooperation with Universidad Francisco de Paula Santander and Universidad de Antioquia.

\section{References}

1. Ni-o L, Pe-uela M, Gelves GR. CFD simulations for improving gas liquid mass transfer in a spin filter bioreactor. International Journal of Applied Engineering Research. 2016; 11(9):6097-108.

2. Olsvik E, Kristiansen B. Rheology of filamentous fermentations. Biotechnology Advances. 1994; 12(1):1-39. https://doi.org/10.1016/0734-9750(94)90288-7

3. Ni-o L. Gelves R. Simulating gas-liquid mass transfer in a spin filter bioreactor. Revista Facultad de Ingeniería Universidad de Antioquia. 2015; 75:163-74.

4. Peixoto SMC, Nunhez JR, Duarte CG. Characterizing the flow of stirred vessels with anchor type impellers. Brazilian Journal of Chemical Engineering. 2000; 17(4-7):925-36. https://doi.org/10.1590/S0104-66322000000400057

5. Jenne M, Reuss M. A critical assessment on the use of $\mathrm{k}$-e turbulence models for simulation of the turbulent liquid flow induced by Rushton turbine in baffled stirred-tank reactors. Chemical Engineering Science. 1999; 54:3921-41. https://doi.org/10.1016/S0009-2509 (99)00093-7

6. Luo J, Issa RI, Gosman AD. Prediction of impeller induced flows in mixing vessels using multiple frames of reference. Institution of Chemical Engineers Symposium Series.1994; 136:549-56. PMid:7532484

7. Micale G, Brucat A, Grisafi F. Prediction of flow fields in a dual-impeller stirred tank. AICHE Journal. 1999; 45(3):445-64. https://doi.org/10.1002/aic.690450303

8. Bakker, Van Den Akker H. A computational model for the gas-liquid flow in stirred reactors. Transactions of IChemE. 1994; 72(4):594-606.

9. Gelves R, Dietrich A, Takors R. Modeling of gasliquid mass transfer in a stirred tank bioreactor agitated by a Rushton turbine or a new pitched blade impeller. Bioprocess and Biosystems Engineering. 2014; 37(3):365-75. https://doi. org/10.1007/s00449-013-1001-8. PMid:23828243

10. Kasat R, Pandit GR. Simulation of Gas-Liquid Flows in a Reactor Stirred by Dual Rushton Turbines. International Journal of Chemical Reactor Engineering. 2008; 6(1):1-28. https://doi.org/10.2202/1542-6580.1628

11. Gabelle J, Jourdier E, Licht RB, Chaabane B, Henaut I, Morchain J, Augier J. Impact of rheology on the mass transfer coefficient during the growth phase of in stirred bioreactors. Chemical Engineering Science. 2012; 75: 408-17. https://doi.org/10.1016/j.ces.2012.03.053

12. Hounslow MJ, Ryall RL, Marschall VR. A Discretized Population Balance for Nucleation, Growth and Aggregation. AIChE Journal. 1988; 34(11):1821-32. https:// doi.org/10.1002/aic.690341108 
13. Ramkrishna D. Population Balances: Theory and Applications to Particulate Systems in Engineering. Academic Press, San Diego; 2000. PMid:11027180

14. Coulaloglou CA, Tavlarides LL. Description of interaction processes in agitated liquid-liquid dispersions. Chemical Engineering Science. 1977; 32(11):1289 -97. https://doi. org/10.1016/0009-2509(77)85023-9
15. Dhanasekharan K, Sanyal J, Jain A, Haidari A. A generalized approach to model oxygen transfer in bioreactors using population balances and computational fluid dynamics. Chemical Engineering Science. 2005; 60(1):213-18. https:// doi.org/10.1016/j.ces.2004.07.118 